\title{
Densitas dan Kegagalan Produksi pada Proses Produksi Genta Bali
}

\author{
I Ketut Gede Sugita ${ }^{1,{ }^{*}}$, I G N Priambadi ${ }^{1}$, Ketut Astawa ${ }^{1}$ \\ ${ }^{1}$ Program Studi Teknik Mesin Universitas Udayana, Kampus Bukit Jimbaran Bali \\ Naskah diterima 30/03/2020; direvisi 05/04/2020; disetujui 15/04/2020 \\ doi: https://doi.org/10.24843/JEM.2020.v013.i01.p05
}

\begin{abstract}
Abstrak
Proses pembuatan lonceng tradisional berbahan perunggu dilakukan dengan proses pengecoran. Bahan yang biasa digunakan dalam produksi lonceng tradisional adalah paduan perunggu denganperbandingan persentase tembaga (Cu) $80 \%$ dan timah (Sn) 20\%. Paduan ini memiliki sifat mekanik dan akustik yang lebih baik dibandingkan dengan kuningan. Tujuan dari penelitian ini adalah untuk menentukan karakteristik kepadatan dan cacat cor dalam proses produksi lonceng tradisional. Paduan perunggu dilebur dalam tungku crucible pada temperatur tuang $1000,1050,1100{ }^{\circ} \mathrm{C}$. Paduan yang telah mencair dituang ke dalam cetakan permanen yang telah dipanaskan terlebih dahulu pada temperatur $200,300,400^{\circ} \mathrm{C}$. Billet hasil coran dipotong-potong dan dimanufacturing untuk pembuatan spesimen uji densitas dan porositas. Hasil penelitian menunjukkan bahwa variasi temperatur penuangan mempengaruhi densitas dan cacat hasil coran. Semakin tinggi temeratur tuang berdampak pada semakin banyak cacat yang terjadi, terutama cacat-cacat porositas. Porositas material yang lebih kecil berpengaruh pada kualitas akustik yang lebih baik.
\end{abstract}

Kata Kunci: Lonceng, perunggu, pengecoran, cacat cor, densitas

\begin{abstract}
The process of making traditional bells made of bronze alloys is a casting process. Materials commonly used in the production of traditional bells are bronze with a percentage of copper $(\mathrm{Cu})$ of $80 \%$ and tin $(\mathrm{Sn})$ of $20 \%$. This alloy has better mechanical and acoustic properties compared to brass. The purpose of this study was to determine the characteristics of density and cast defects in the traditional bell production process. The bronze alloy was melted in a crucible furnace at a temperature of 1000 , $1050,1100^{\circ} \mathrm{C}$. The melted alloys were poured into a permanent mold that has been heated at a temperature of $300^{\circ} \mathrm{C}$. Castings billets were cut into pieces and manufactured for making density and casting defect test specimens. The results showed that the variation of the pouring temperature affected the density and casting defects. The higher the pouring temperature has an impact on the more cast defects, especially the porosity of the cast. Low porosity affects better acoustic quality.
\end{abstract}

Keywords: traditional bells, bronze, casting, defect, density

\section{Pendahuluan}

High tin bronze merupakan paduan perunggu yang terdiri dari paduan utama yaitu tembaga $(\mathrm{Cu})$ dan timah putih (Sn). Paduan perunggu dengan komposisi $80 \% \mathrm{Cu}-20 \%$ Sn, umumnya digunakan sebagai bahan alat musik seperti lonceng, gamelan. Paduan ini memiliki sifat mekanik yang baik, stabil dalam kondisi temperatur kamar dan sifat akustik yang baik dan mampu menghasilkan getaran yang tahan lama (getaran redaman rendah) (Lisovskii, 2007, Hosford, 2005).

Proses utama dalam pembuatan lonceng tradisional (genta) adalah proses pengecoran (casting) yaitu proses tertua dalam proses pembentukan, yang dikenal dalam memproduksi komponen logam. Pengecoran memiliki beberapa keunggulan, yaitu proses ini dapat menghasilkan produk dengan bentuk yang kompleks atau rumit, mampu memproduksi produk dengan ukuran besar dan kecil dan menghasilkan produk bentuk bersih dalam produksi massal dengan Biaya yang rendah. Sebagian besar proses produksi dilakukan dengan proses casting (Stefanescu, 2002). Salah satu parameter penting dalam proses casting adalah proses solidifikasi (solidification).
Beberapa penelitian tentang proses solidifikasi telah dilakukan oleh beberapa peneliti seperti: proses solidifkasi dalam sistem paduan biner (Lee, 1995), proses solidifikasi paduan perunggu $\mathrm{Cu}-8 \% \mathrm{Sn}$ (Martorano dan Capocchi, 2000), solidifikasi dalam cetakan permanen (Shepel, 2002, Vijayaram, et al., 2006), solidifikasi cepat paduan timah-timah solder Sn$\mathrm{Cu}$ (Shen, dkk. 2006), laju solidifikasi besi tuang (Seah, et al., 1998), laju solidifikasi besi tuang (ductile cast iron) (Hemanth, 2000), laju solidifikasi aluminiumA356 (Zhang, et al., 2008). Variasi temperatur cetakan dan temperatur penuangan mempengaruhi laju pembekuan. Aplikasi temperatur awal cetakan yang telah diteliti yaitu temperatur $450-500^{\circ} \mathrm{C}$ (Kaplan, et al.,2003) dan temperatur $300-400^{\circ} \mathrm{C}$ (Campbell, 2003). Pemanasan awal cetakan pada temperatur $300-400^{\circ} \mathrm{C}$ pada pengecoran sistem gravitasi dan tekanan tinggi, dapat meningkatkan fluiditas casting. Jika temperatur cetakan mendekati temperatur paduan cair, fluiditas menjadi tak terbatas (Campbell, 2003).

Sifat mekanis dan fisik dari hasil pengecoran tergantung pada perilaku solidifikasi yang ditentukan oleh proses kontrol selama solidifikasi. Proses solidifikasi mempengaruhi struktur mikro yang 
berdampak langsung pada sifat-sifat mekanis dari paduan hasil coran. Efek mikrostruktur pada sifat paduan logam telah ditunjukkan dalam berbagai penelitian, khususnya, efek dendrite arm spacing pada sifat mekanik, yaitu, kekuatan tarik maksimum (UTS). Pengaruh laju pendinginan pada dendrite arm spacing (DAS) telah diteliti oleh Wislei R (2004), Joel Hemanth (1999), Zhang, LY (2007), Silva Talamantes, (2008), Seah, (1997), Hasil penelitian tersebut, secara umum menunjukkan bahwa, laju pendinginan solidifikasi memiliki efek yang nyata pada dendrite arm spacing. UTS berkurang dengan meningkatnya dendrite arm spacing.

Tujuan dari penelitian ini adalah untuk untuk mengetahui pengaruh variasi produksi pada pengecoran genta terhadap densitas dan cacat produksi genta.

\section{Metode Penelitian}

Bahan yang digunakan dalam penelitian ini, sebagai bahan pembuatan genta adalah paduan perunggu (tin bronze) dengan perbandingan tembaga dengan timah putih 10:3. Gambar 1 menunjukkan mekanisme proses pengcoran dalam proses pembuatan genta. Tembaga (pure commercial) dan timah putih (Gbr 1.a) dilebur dalam tungku (crucible furnace) pada temperatur $1000^{\circ} \mathrm{C}$ (gambar $1 \mathrm{~b}$ ). Bahan yang telah dicairkan dituangkan ke dalam cetakan yang telah dipanaskan pada variasi temperatur $200,300,400^{\circ} \mathrm{C}$ (gambar 1c), Pemanasan cetakan bertujuan untuk menghindari temperatur kejut antara paduan cair yang dituangkan ke dalam cetakan dengan dinding cetakan. Logam cair yang dituangkan ke dalam cetakan akan mengisi ruang cetakan yang ditandai dengan saluran cetakan terisi penuh oleh cairan logam. Pelepasan cetakan dilakukan setelah panas cetakan berkurang menjadi 150-100ㄷ. Termokopel tipe $\mathrm{K}$, digunakan untuk mengukur temperatur solifikasi selama proses pengecoran.

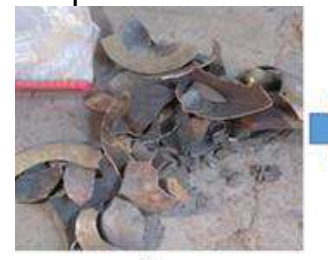

a

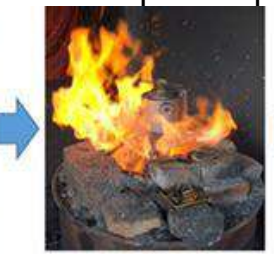

\begin{abstract}
b
\end{abstract}

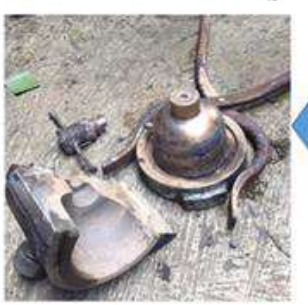

e
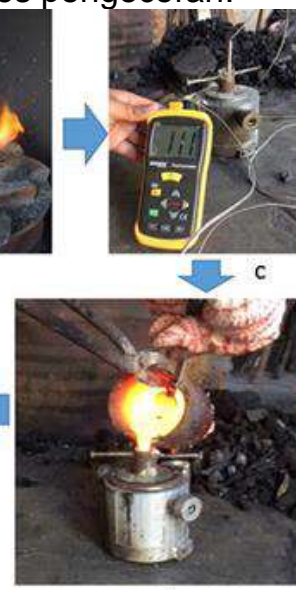

d
Gambar 1. Mekanisme produksi genta

a. Material dasar (bronze)

b. Proses peleburan

c. Pengukuran temperature cetakan

d. proses penuangan

e. Pembongkaran hasil coran

Hasil coran kemudian dimanufaktur untuk pembuatan spesimen, uji densitas dan cacat coran genta. Karakteristik mikrostruktur hasil coran dievaluasi dengan menggunakan mikroskop optic. Spesimen untuk investigasi metalografi disiapkan dengan memotong spesimen dari coran. Setelah dipotong, spesimen dipoles menggunakan kertas abrasif silikon karbida (amplas) dengan tingkat kekasaran masing-masing: 240, 400, 600, 800, 1000, 2000 grit, dan kemudian dipoles ulang dengan sempurna menggunakan pasta berlian dan dietsa dengan 10\% HNO3 + 90\% alkohol. Prosedur ini diterapkan mengikuti teknik standar metalografi. Komposisi kimia paduang perunggu yang digunakan dalam penelitian uini ditunjukkan pada Tabel 1 .

Tabel 1. Komposisi paduan perunggu

\begin{tabular}{|l|l|l|l|l|l|l|l|l|}
\hline Bahan & \multicolumn{7}{|c|}{ Kandungan elemen \%wt } \\
\cline { 2 - 9 } Perunggu & $\mathrm{Cu}$ & $\mathrm{Sn}$ & $\mathrm{Si}$ & $\mathrm{Pb}$ & $\mathrm{Zn}$ & $\mathrm{Mn}$ & $\mathrm{S}$ & As \\
\hline Cu-20Sn & 79.18 & $19-1$ & - & 1.18 & 0.505 & 0.0008 & 0.004 & 0.055 \\
\hline
\end{tabular}

\section{Hasil dan Pembahasan}

\subsection{Densitas coran}

Persentase porositas yang terjadi pada hasil coran, dapat ditentukan dengan menghitung atau membandingkan kerapatan sampel dengan kerapatan teoritis. Densitas adalah kuantitas fisik yang merupakan rasio massa $(\mathrm{m})$ terhadap volume objek (v). Metode Archimedes digunakan untuk mengukur kepadatan material dalam bentuk padatan. Persamaan untuk menghitung kerapatan sampel dan nilai teoritik ditunjukkan pada persamaan berikut:

\section{dimana}

$$
\rho_{m}=\frac{m_{s}}{\left(m_{s}-m_{g}\right)} \times \rho_{\mathrm{H}_{2} \mathrm{O}}
$$

$$
\begin{aligned}
& \rho_{m}=\text { kepadatan sampel }\left(\mathrm{g} / \mathrm{cm}^{3}\right) \\
& m_{s}=\text { massa sampel kering }(\mathrm{g}) \\
& m_{g}=\text { Massa sample yang direndam dalam air }(\mathrm{g}) \\
& \rho \mathrm{H}_{2} \mathrm{O}=\text { Kepadatan air }\left(1 \mathrm{~g} / \mathrm{cm}^{3}\right)
\end{aligned}
$$

Persentase porositas spesimen dihitung menggunakan persamaan berikut:

$$
\% \text { porositas }=\left[1-\frac{\rho_{b}}{\rho_{t h}}\right] \times 100
$$

Dimana $\rho_{\text {th }}$ adalah kerapatan teoritis paduan.

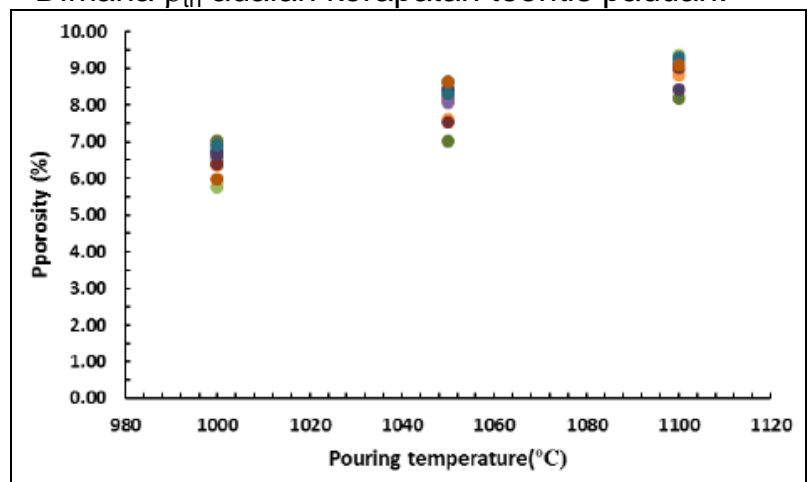

Gambar 2. Pengaruh temperatur tuang (pouring temperature) terhadap porositas

Hasil pengujian diplot dalam grafik yang disajikan pada Gambar 2 yang menunjukkan bahwa semakin tinggi temperatur penuangan berdampak pada lebih banyak porositas atau cacat yang terjadi pada hasil coran. Temperatur yang lebih tinggi menyebabkan turbulensi dalam aliran logam pada sauran tuang. Gerakan turbulensi aliran menimbulkan gelembung air yang kemudian terperangkap selama proses pembekuan. Udara yang terperangkap dalam proses 
solidifikasi membentuk lubang-lubang kecil didalam coran yang sering disebut porositas.

\subsection{Cacat coran}

Cacat coran seperti lubang pin (Gambar $3 \mathrm{~s} / \mathrm{d}$ 5) disebabkan oleh adanya gas hidrogen yang diserap dalam logam cair selama proses penuangan dan pembekuan. Karakteristik lubang pin adalah lubang kecil seperti jarum dengan panjang kurang dari $1 \mathrm{~mm}$.

Menurut Rajesh Rajkolhe (2104), salah satu yang terjadi porositas Penyusutan adalah gas hidrogen yang dicampur atau digabungkan dalam logam cair selama proses penuangan logam ke dalam cetakan dan proses pembekuan yang terlalu lama.

Gambar 3 s/d 5 menunjukkan porositas gas yang disebabkan oleh gas yang terperangkap dalam material cor. Porositas karena penyusutan juga terjadi karena pemadatan atau penyusutan selama titik beku yang tidak merata. Hasil coran juga menunjukkan adanya cacat inklusi karena pengotor yang ada terperangkap dalam logam cair selama proses solidifikasi.

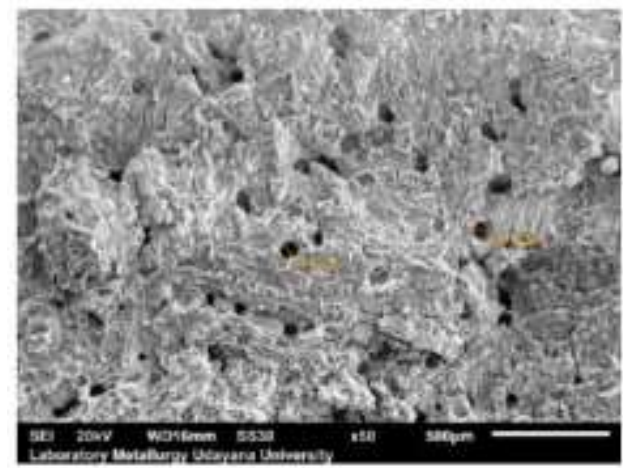

Gambar 3. Cacat coran perunggu hasil pengecoran pada temperature tuang $1000^{\circ} \mathrm{C}$ dan temperatur cetakan $200^{\circ} \mathrm{C}$

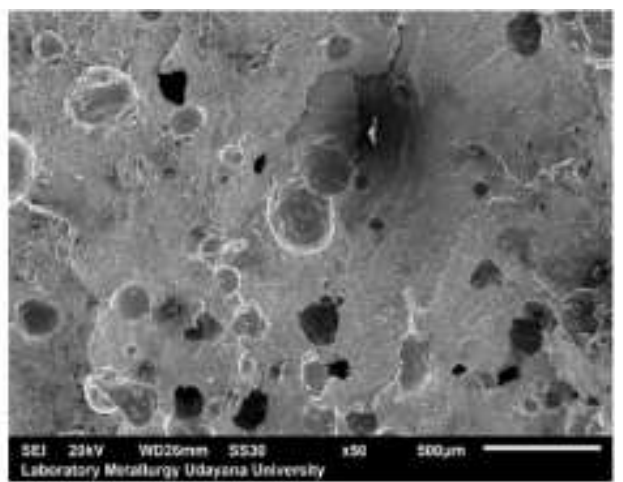

Gambar 4. Cacat coran perunggu hasil pengecoran pada temperature tuang $1050^{\circ} \mathrm{C}$ dan temperatur cetakan $200^{\circ} \mathrm{C}$

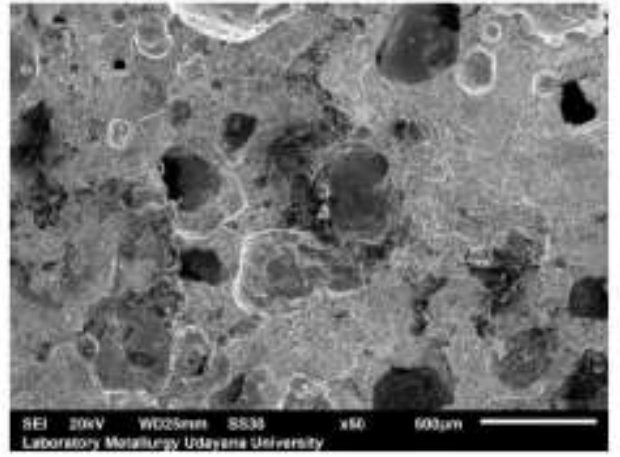

Gambar 5. Cacat coran perunggu hasil pengecoran pada temperature tuang $1100^{\circ} \mathrm{C}$ dan temperatur cetakan $200^{\circ} \mathrm{C}$

\subsection{Laju solidifikasi dan struktur mikro}

Pengamatan pada struktur mikro menunjukkan bahwa variasi laju solidifikasi telah mempengaruhi pembentukan bentuk struktur mikro. Bentuk struktur mikro diamati pada semua spesimen yang diuji dengan variasi laju pendinginan. Hasil penelitian menunjukkan bahwa ada korelasi erat antara variabel temperatur, laju pendingingan. Variasi laju solidifikasi berpengaruh langsung terhadap bentuk struktur mikro, seperti ukuran butir dan jarak lengan dendritik, juga tergantung pada kondisi perpindahan panas yang antara logam cair dan dinding cetakan selama proses pendinginan.

Mikrostruktur yang terbentuk dari fase interdendritik. Butiran halus (Gambar $6 \mathrm{~s} / \mathrm{d}$ 8) terjadi karena gradien termal antara permukaan cetakan yang didinginkan dan logam cair tinggi. Di sisi lain, pendinginan lambat berpengaruh pada pertumbuhan dari beberapa inti sehingga menghasilkan struktur butiran kasar.

Ukuran dendrit yang dihasilkan pada proses pengecoran dengan temperatur cetakan yang lebih rendah memiliki stutur yang lebih halus dengan sifat fisis terbaik dari tiga proses yang diujikan, hal ini disebabkan oleh proses laju pembekuan yang cepat, yang dihasilkan oleh koefisien perpindahan panas yang lebih tinggi antara logam cair dan cetakan.

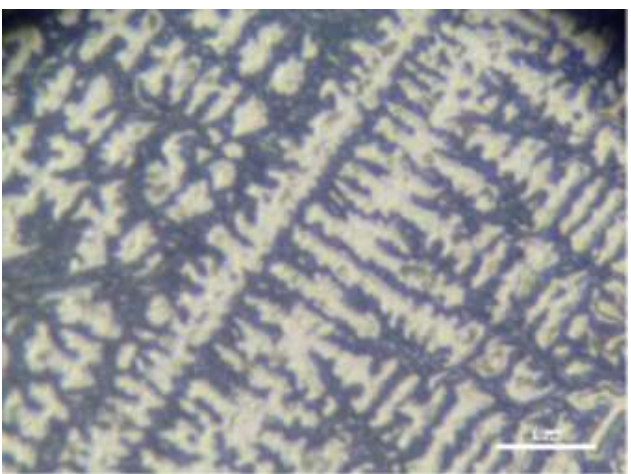

Gambar 6. Mikrostruktur perunggu pada pada temperatur tuang $1000^{\circ} \mathrm{C}$ dan temperatur cetakan $200^{\circ} \mathrm{C}$ (pembesaran, 100x) 


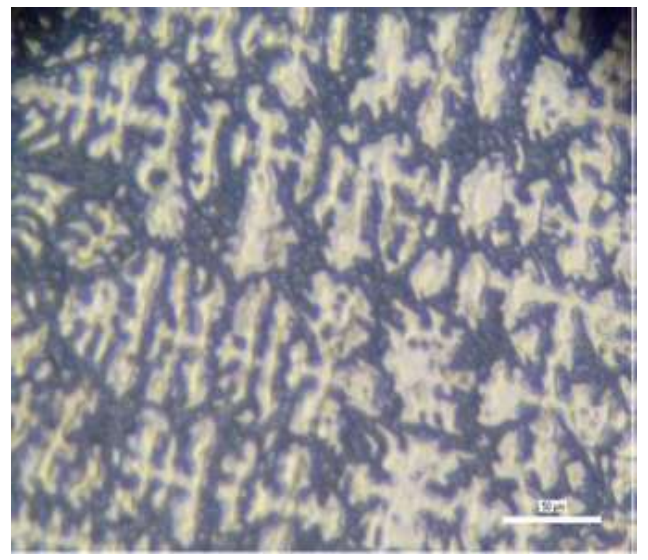

Gambar 7. Mikrostruktur perunggu pada pada temperatur tuang $1000^{\circ} \mathrm{C}$ dan temperatur cetakan $300^{\circ} \mathrm{C}$ (pembesaran, 100x)

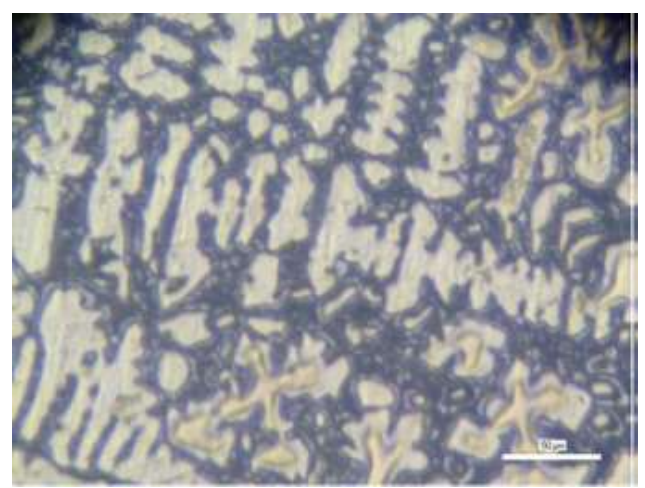

Gambar 8. Mikrostruktur perunggu pada pada temperatur tuang $1000^{\circ} \mathrm{C}$ dan temperatur cetakan $400^{\circ} \mathrm{C}$ (pembesaran, 100x)

\section{Simpulan}

Berdasarkan hasil dan analisis data, proses pengecoran pada berbagai temperatur cetakan menunjukkan bahwa variasi temperatur penuangan dan temperatur cetakan mempengaruhi kepadatan dan porositas tuang cor. Semakin tinggi temperatur penuangan berdampak pada semakin banyak porositas yang terjadi. Bentuk mikro dipengaruhi oleh tingkat pemadatan dalam proses produksi genta.

\section{Ucapan Terima Kasih}

Ucapan terima kasih atau penghargaan bisa disampaikan kepada Fakultas Teknik, dan LPPM Universitas Udayana yang telah mendanai penelitian ini dalam skim Hibah Unggulan Udayana.

\section{Daftar Pustaka}

[1] Callister, W., 2001, Fundamental of Materials Science and Engineering John Wiley and Son Inc. pp. 179.

[2] Campbell, J., 2003, The New Metallurgy of Cast Metals, Second Edition, Butterworth Heinemann

[3] Favstov Yu. K, Zhravel,L.V., Kochetkova, L.P., 2003, Structure and Damping Capacity of BrO22 Bell Bronze, Journal Metal science and Heat treatment, Vol.45, pp. 449-451.

[4] Gupta R.B., 2001, Materials Science, Tech India Publication.
[5] Halvaee, A. and Talebi, A., 2001, Effect of Process Variables on Microstructure and Segregation in Centrifugal Casting of C92200 Alloy, Journal of Materials Processing Technology 118, pp 123-127.

[6] Hosford F. William, 2005, Mechanical Behaviour of Materilas, Cambridge University Press

[7] Kaplan, M. and Yieldiz, A.K., 2003, The Effects of Production Methods on Microstructures and Mechanical Properties of an Aluminum Bronze, Materials Letters, pp.4402-4411.

[8] Lisovskii,V.A, Lisovskaya.O.B, Kochetkova,L.P, Favstov, Yu.K, 2007, Sparingly Alloyed Bell Bronze with Elevated Parameters of Mechanical Properties, Journal Metal

[9] Martorano, M.,A. and Capocchi, J., D.,T., 2000, Heat Transfer Coefficient at the Metal-Mould Interface in the Unidirectional Solidification of $\mathrm{Cu}$ $8 \%$ Sn Alloys, Journal of Heat and Mass Transfer vol. 43 pp.2541-2552.

[10] Schmidt R.F., Schmidt D.G., 1993, Selection and Application of Copper Alloy Castings, ASM Handbook, Metals Handbook, Vol. 2, American Society of Metals, Cleveland, OH, p. 346.

[11] Sugita I Ketut Gede, I Gusti Ngurah priambadi, 2007, Analisa penggunaan media pendingin pada proses pendinginan perunggu gambelan Bali, Jurnal Teknik mesin UNUD, CAKRAM. Volume 2 No 1, ISSN 1907 - 7467.

[12] Sugita, I Ketut Gede, Soekrisno,R., Miasa, I Made, Suyitno, 2010, The Effect of Solidification Rate on Morphology Microstructures and Mechanical Properties of $80 \% \mathrm{Cu}-20 \%$ Sn Bronze Alloys, Material Sci. Research India Vol 07 No 01.

[13] Sugita, I Ketut Gede, Soekrisno, R., Miasa, I Made, Suyitno, 2011. The Effect of Annealing Temperature on Damping Capacity of the Bronze $20 \%$ Sn Alloy, International Journal of Mechanical \& Mechatronics Engineering. IJMME/IJENS. Vol 11 No 04.

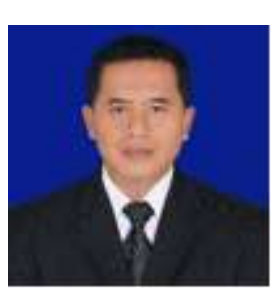

I Ketut Gede Sugita menyelesaikan pendidikan S1 Teknik Mesin di Program Studi Teknik Mesin Univ, Udayana pada tahun 1990. Pendidikan S2: Teknik Mesin - ITS, Surabaya, tahun lulus 2003 dan Pendidikan S3: Teknik Mesin, Universitas Gadjah Mada, tahun lulus 2012.

Hingga saat ini focus penelitian yang dilakukan adalah material perunggu sebagai material dan akustik music gamelan, Proses casting gamelan 